\title{
What Drives Consumers to Shop Online? A Literature Review
}

Citation for published version (APA):

Perea y Monsuwe, T., Dellaert, B. G. C., \& de Ruyter, J. C. (2004). What Drives Consumers to Shop Online? A Literature Review. International Journal of Service Industry Management, 15(1), 102-121. https://doi.org/10.1108/09564230410523358

Document status and date:

Published: 01/01/2004

DOI:

10.1108/09564230410523358

Document Version:

Publisher's PDF, also known as Version of record

\section{Please check the document version of this publication:}

- A submitted manuscript is the version of the article upon submission and before peer-review. There can be important differences between the submitted version and the official published version of record.

People interested in the research are advised to contact the author for the final version of the publication, or visit the DOI to the publisher's website.

- The final author version and the galley proof are versions of the publication after peer review.

- The final published version features the final layout of the paper including the volume, issue and page numbers.

Link to publication

\footnotetext{
General rights rights.

- You may freely distribute the URL identifying the publication in the public portal. please follow below link for the End User Agreement:

www.umlib.nl/taverne-license

Take down policy

If you believe that this document breaches copyright please contact us at:

repository@maastrichtuniversity.nl

providing details and we will investigate your claim.
}

Copyright and moral rights for the publications made accessible in the public portal are retained by the authors and/or other copyright owners and it is a condition of accessing publications that users recognise and abide by the legal requirements associated with these

- Users may download and print one copy of any publication from the public portal for the purpose of private study or research.

- You may not further distribute the material or use it for any profit-making activity or commercial gain

If the publication is distributed under the terms of Article $25 \mathrm{fa}$ of the Dutch Copyright Act, indicated by the "Taverne" license above, 
IJSIM

15,1

102

\title{
What drives consumers to shop online? A literature review
}

\author{
Toñita Perea y Monsuwé, Benedict G.C. Dellaert and \\ Ko de Ruyter \\ Maastricht University, Maastricht, The Netherlands
}

Keywords Information media, Internet, Purchasing, Shopping

Abstract While a large number of consumers in the US and Europe frequently shop on the Internet, research on what drives consumers to shop online has typically been fragmented. This paper therefore proposes a framework to increase researchers' understanding of consumers' attitudes toward online shopping and their intention to shop on the Internet. The framework uses the constructs of the Technology Acceptance Model (TAM) as a basis, extended by exogenous factors and applies it to the online shopping context. The review shows that attitudes toward online shopping and intention to shop online are not only affected by ease of use, usefulness, and enjoyment, but also by exogenous factors like consumer traits, situational factors, product characteristics, previous online shopping experiences, and trust in online shopping.

\section{Introduction}

Despite the slowing penetration of regular Internet users, the number of consumers using the Internet to shop for consumer goods and services is still growing (Forrester Research, December 2001). Research from the GfK Group (2002) shows that the number of online shoppers in six key European markets has risen to 31.4 percent from 27.7 percent last year. This means that 59 million Europeans use the Internet regularly for shopping purposes. However, not only does the number of online shoppers grow, the volume of their purchases also increases over-proportionally. In the US, online sales are forecasted to exceed $\$ 36$ billion in 2002, and grow annually by 20.9 percent to reach $\$ 81$ billion in 2006. Europeans are spending more money online as well. For instance, Europe's largest discount carrier, easyJet Airline Co., sold $\$ 80$ million more tickets online in the six months ended March 31 than it did a year earlier (Reinhardt and Passariello, 2002), whereas combined revenues for Amazon.com's European operations grew at more than 70 percent annually in each of the past three quarters, topping $\$ 218$ million.

While these figures show that a large number of consumers in the US and Europe frequently use the Internet for shopping purposes, it is not clear what drives them to shop online and whether these numbers could be even increased

International Journal of Service Industry Management

Vol. 15 No. 1, 2004

pp. 102-121

(c) Emerald Group Publishing Limited 0956-4233

DOI $10.1108 / 09564230410523358$
This research was sponsored by a grant of KLICT (Ketennetwerken, Clusters and ICT), for which the authors extend their thanks. The authors would also like to thank Jan-Simon Swagemakers from Fujitsu Services BV, Jeroen Brouwers and Niels Goossens from Elitech, and Tom W.J. Koppelman from ABP Advies for their practical and managerial insights on online shopping. For their supportive comments, the authors also thank two reviewers from KLICT: Hans van Trijp and Eelko Huizingh. 
if more attractive online stores were developed. This raises the issue of examining what factors affect consumers to shop online. Therefore, a framework is needed to structure the complex system of effects of these different factors, and develop an in-depth understanding of consumers' attitudes toward Internet shopping and their intentions to shop online.

In this study, we build up such a framework based on previous research on consumer adoption of new self-service technologies and Internet shopping systems (Dabholkar and Bagozzi, 2002; O'Cass and Fenech, 2002; Childers et al., 2001; Davis, 1993). This research suggests that consumers' attitude toward Internet shopping first depends on the direct effects of relevant online shopping features (Davis, 1993). Online shopping features can be either consumers' perceptions of functional and utilitarian dimensions, like "ease of use" and "usefulness", or their perceptions of emotional and hedonic dimensions like "enjoyment" (Menon and Kahn, 2002; Childers et al., 2001; Mathwick et al., 2001). By including both utilitarian and hedonic dimensions, aspects from the information systems or technology literature, as well as the consumer behavior literature are integrated in our framework. In addition to these relevant online shopping features, also exogenous factors are considered that moderate the relationships between the core constructs of the framework. Relevant exogenous factors in this context are "consumer traits" (Burke, 2002; Dabholkar and Bagozzi, 2002; Brown et al., 2001; Eastin and LaRose, 2000), "situational factors" (Wolfinbarger and Gilly, 2001; Avery, 1996), "product characteristics" (Grewal et al., 2002; Elliot and Fowell, 2000), "previous online shopping experiences" (Shim et al., 2001; Eastlick and Lotz, 1999), and "trust in online shopping" (Yoon, 2002; Lee and Turban, 2001). By incorporating these exogenous factors next to the basic determinants of consumers' attitude and intention to use a technology, the framework is applicable in the online shopping context. Together, these effects and influences on consumers' attitude toward online shopping provide a framework for understanding consumers' intentions to shop on the Internet. An important note to our proposed framework is that throughout this paper we will define Internet shopping or online shopping as the use of online stores by consumers up until the transactional stage of purchasing and logistics.

The outline of the paper is as follows. In the next section, we first introduce a framework containing all constructs that affect consumers' attitude and intentions to shop on the Internet. Second, we examine the basic determinants of consumers' attitude and intentions: "usefulness", "ease of use" and "enjoyment". Third, since it has been argued that "consumer traits" moderate the relationship between the three basic determinants and attitude, and "situational factors", "product characteristics", "previous online shopping experiences", and "trust in online shopping" moderate the relationship between consumers' attitude and intentions, an examination of the influence of these factors is presented. Fourth, we investigate the differences, similarities, 
IJSIM

15,1

104 advantages, and disadvantages of online shopping and traditional shopping features. Finally, we summarize our findings and discuss the practical and theoretical implications, as well as the limitations of this paper.

\section{Framework for consumers' intentions to shop on the Internet}

For developing an in-depth understanding of consumers' attitudes toward online shopping and their intentions to shop on the Internet, we built up a framework (Figure 1), based on previous research on consumer adoption of new technologies and services. As noted earlier, in this framework "online shopping" is defined as the use of online stores by consumers up until the transactional stage of purchasing and logistics. The core constructs of our framework are adapted from the Technology Acceptance Model (TAM) by Davis (1989), an influential research model in the information systems field. Although this model is specifically tailored to understand the adoption of computer-based technologies on the job or in the workplace, it has proven to be suitable as a theoretical foundation for the adoption of e-commerce as well (Chen et al., 2002; Moon and Kim, 2001; Lederer et al., 2000). Therefore, the TAM constructs are used as a basis for our research framework.

In TAM, behavioral intention to use a new technology is determined by the individual's attitude toward using this technology. To this, TAM originally identifies two, conceptually independent, determinants of a person's attitude toward using a new technology. The first determinant is "usefulness", and refers to the degree to which a person believes using the new technology will improve his/her performance or productivity. TAM also identifies a second determinant, "ease of use", referring to the extent to which a person believes that using the new technology will be free of effort. While "usefulness" refers to consumers' perceptions regarding the outcome of the experience, "ease of use" refers to their perceptions regarding the process leading to the final outcome.

A more recent addition to the technology acceptance model is the "enjoyment" construct, or the extent to which the activity of using the new technology is perceived to provide reinforcement in its own right, apart from any performance consequences that may be anticipated (Davis et al., 1992). Thus, within the TAM framework, both utilitarian and hedonic aspects are considered to act as determinants of consumers' attitude toward using a new technology. Understanding the determinants of consumers' attitude, it is argued that this attitude has a strong, direct, and positive effect on consumers' intentions to actually use the new technology or system (Bobbitt and Dabholkar, 2001; Davis, 1993).

Although TAM has proven to be a viable model for examining consumer acceptance of new technologies and systems, it is necessary, however, for the purpose of defining more specific drivers of consumer acceptance of new Internet technology, to extend this model by incorporating additional factors 


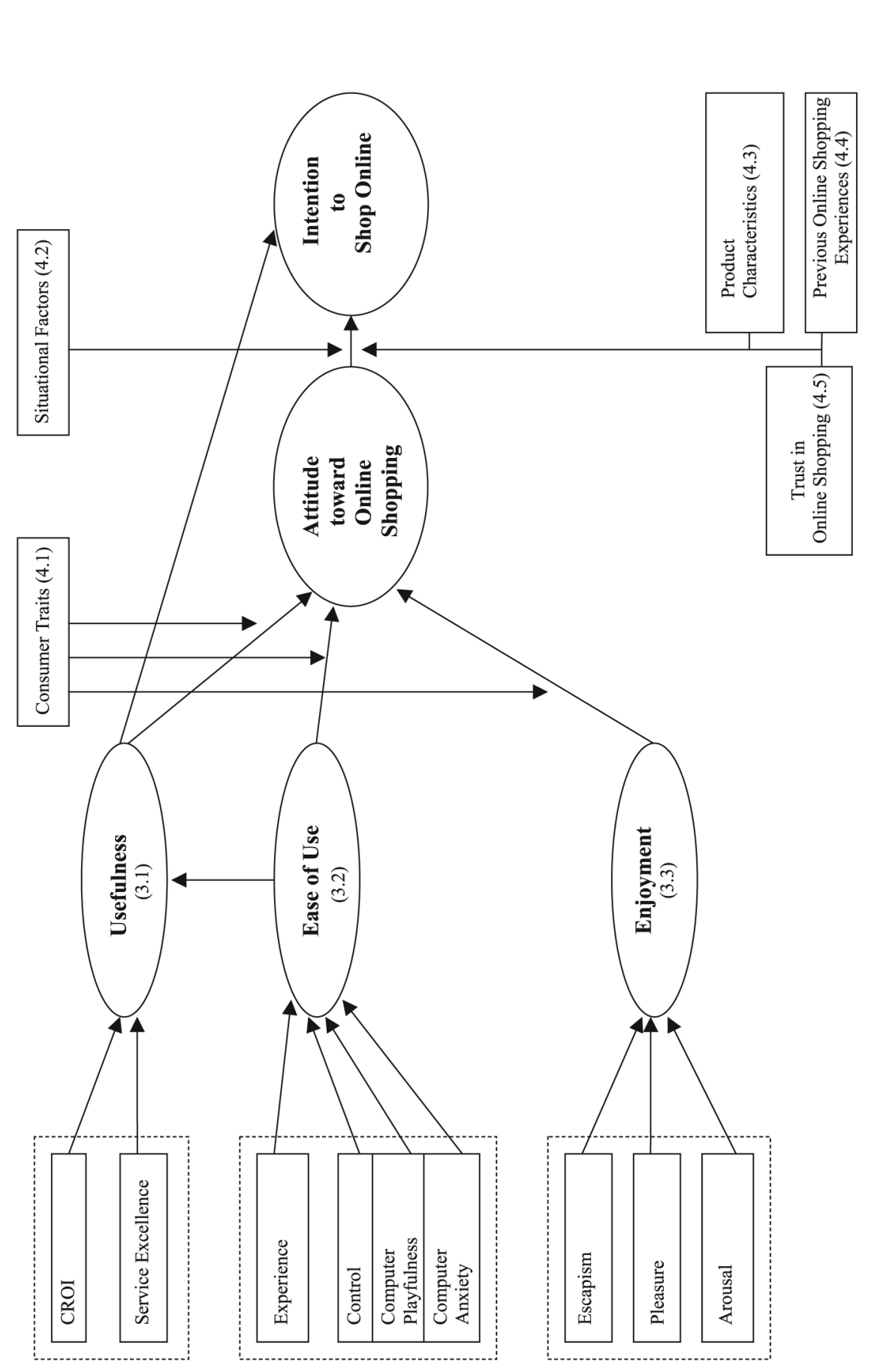

Online shopping

105

Figure 1.

Framework for consumers' intentions to shop online 
IJSIM

15,1

106

in our research framework. The major reason for this is that these exogenous variables improve the viability and predictive nature of TAM, and enable its application in the environment of online shopping. For instance, Venkatesh (2000) already suggested integrating additional factors like "control" (computer self-efficacy), "intrinsic motivation" (computer playfulness), and "emotion" (computer anxiety) into the existing technology acceptance model. These factors are proposed to act as significant determinants for "ease of use", one of the basic constructs of TAM. Dabholkar and Bagozzi (2002) add the influences of two other exogenous factors, e.g. "consumer traits" and "situational influences" to the TAM framework, resulting in an attitudinal model of technology-based self-service. Also, O'Cass and Fenech (2002) have extended TAM by adding seven key consumer characteristics: "opinion leadership", "buying impulsiveness", "satisfaction with Web sites", "Web shopping compatibility", "shopping orientation”, "Internet self-efficacy”, and “ Web security". For the purpose of this paper, besides "ease of use", "usefulness", and "enjoyment", we integrate five exogenous factors into our framework for understanding consumers' intentions to use the Internet as a shopping medium: "consumer traits", "situational factors", "product characteristics", "previous online shopping experiences", and the "trust in online shopping”.

After introducing the basic determinants and all relevant exogenous factors of our research framework in this section, the next section of this paper elaborates on each factor separately, relating to their respective influence on consumers' attitude and intentions to shop on the Internet. Focusing first on the influences of the three basic constructs adapted from TAM, we will then move on to discuss the effects of the exogenous factors incorporated in our framework.

\section{Basic determinants of attitude and intentions toward online shopping}

Motivations of consumers to engage in online shopping include both utilitarian and hedonic dimensions. Whereas some Internet shoppers can be described as "problem solvers", others can be termed seeking for "fun, fantasy, arousal, sensory stimulation, and enjoyment" (Hirschman and Holbrook, 1982). The problem solvers merely shop online in order to acquire a specific product or service, in which case shopping is considered to be "an errand" or "work" (Babin et al., 1994). Their main concern is to purchase products in an efficient and timely manner to achieve their goals with a minimum of irritation. In contrast, the second category sees online shopping as "enjoyment" and seeks for the potential entertainment resulting from the fun and play arising from the Internet shopping experience. They appreciate the online shopping experience for its own sake, apart from any other consequence like, for example, an online purchase that may result (Holbrook, 1994). This dual characterization of 
consumers' motivations for online shopping is consistent with our framework: whereas "usefulness" and "ease of use" reflect the utilitarian aspects of online shopping, "enjoyment" embodies the hedonic aspect. The next three paragraphs elaborate on the discussion that both utilitarian and hedonic factors ultimately affect consumers' attitude toward shopping on the Internet.

Usefulness

"Usefulness" is defined as the individual's perception that using the new technology will enhance or improve her/his performance (Davis, 1989, 1993). Applying this definition to our research context, as the new technology we classify shopping on the Internet, and as the individual's performance the outcome of the online shopping experience. Then, "usefulness" refers to consumers' perceptions that using the Internet as a shopping medium enhances the outcome of their shopping experience. These perceptions influence consumers' attitude toward online shopping and their intention to shop on the Internet. TAM posits a weak direct link between "usefulness" and attitude, and a strong direct link between "usefulness" and intention (Davis et al., 1989). This was explained as originating from consumers intending to use a technology because it was useful, even though they did not have a positive affect toward using. Apart from this, "usefulness" is also linked with "ease of use" to determine consumers' attitude toward online shopping. According to TAM, "usefulness" is influenced by "ease of use", because the easier a technology is to use, the more useful it can be (Venkatesh, 2000; Dabholkar, 1996; Davis et al., 1989).

In our framework, we include two latent dimensions of the "usefulness" construct: "consumer return on investment (CROI)", and "service excellence" (Mathwick et al., 2001). Both dimensions are extrinsic value-based perceptions and serve as performance indicators for shopping on the Internet. "CROI" is the perceived return on cognitive, behavioral, or financial investments made by the consumer. By investing in a computer and learning to shop on the Internet, the consumer expects a desired result, such as an online search or Web purchase, in return from shopping on the Internet. If this return meets their expectations, consumers' "usefulness" of the Internet as a shopping medium will be positive. "Service excellence" is the consumer's appreciation of delivered promises and performed functions. Service excellence operates as an ideal, a standard against which judgments are ultimately formed (Holbrook, 1994). If online shopping meets this ideal by enabling the consumer to accomplish the shopping task he or she has set out to perform, then consumers will judge the Internet shopping performance positively (Mathwick et al., 2002). This leads to positive perceptions regarding the usefulness of online shopping.

\section{Ease of use}

"Ease of use" is defined as the individual's perception that using the new technology will be free of effort (Davis, 1989, 1993). Applying this to our 
IJSIM

15,1

108

research context, "ease of use" is the consumer's perception that shopping on the Internet will involve a minimum of effort. Whereas "usefulness" referred to consumers' perceptions regarding the outcome of the online shopping experience, "ease of use" refers to their perceptions regarding the process leading to the final online shopping outcome. In a simplified manner, it can be stated that "usefulness" is how effective shopping on the Internet is in helping consumers to accomplish their task, and "ease of use" is how easy the Internet as a shopping medium is to use. According to TAM, "ease of use" has a dual effect, direct as well as indirect, on consumers' intention to shop online. The indirect effect on intention is through "usefulness", as already explained in the previous section. The direct effect is explained by the fact that in behavioral decision making consumers attempt to minimize effort in their behaviors, as is also the case with consumers' perceptions regarding the "ease of use": the perception that Internet shopping will be free of effort (Venkatesh, 2000). The easier and more effortless a technology is, the more likely consumers intend to use this technology.

Understanding that "ease of use" affects consumers' attitude and intention toward online shopping, it is important to identify the latent dimensions of this construct in the Internet setting. According to TAM, "ease of use" is particularly of influence in the early stages of user experience with a technology or system (Davis, 1989, 1993). Following this, Venkatesh (2000, p. 343) stated: “...With increasing direct experience with the target system, individuals adjust their system-specific ease of use to reflect their interaction with the system". Implying that if consumers get more experienced with Internet, they will adjust their perceptions regarding the "ease of use" of the Internet as a shopping medium in a positive direction. Besides "experience" with the technology or system, also three other latent dimensions of the "ease of use" construct are incorporated in our framework: "control", "computer playfulness", and "computer anxiety" (Venkatesh, 2000). "Control” relates to an individual's perception of the availability of knowledge, resources, and opportunities required to perform a specific behavior, in our case online shopping. "Computer playfulness" is the degree of cognitive spontaneity in computer interactions. Playful individuals may tend to underestimate the difficulty of the means or process of online shopping, because they quite simply enjoy the process and do not perceive it as being effortful compared to those who are less playful (Venkatesh, 2000). "Computer anxiety" is defined as an individual's apprehension or even fear when she/he is faced with the possibility of using computers. This influences consumers' perceptions regarding the "ease of use" of the Internet as a shopping medium in a negative way, since using a computer is one of the necessary requirements for online shopping.

In addition to these four latent dimensions, "site characteristics" like search functions, download speed, and navigation, also play a role in shaping "ease of use"(Zeithaml et al., 2002). But since these site characteristics merely influence 
the "ease of use" of a particular Web site or online store, and not the Internet as a shopping medium in general, we choose not to elaborate on these site characteristics for the purpose of this paper.

\section{Enjoyment}

Next to the evidence for the critical role of extrinsic motivation for technology use (Hirschman and Holbrook, 1982; Babin et al., 1994), there is a significant 109 body of theoretical and empirical evidence regarding the importance of the role of intrinsic motivation (Davis et al., 1992; Venkatesh and Speier, 1999, 2000). Intrinsic motivation for Internet shopping is captured by the "enjoyment" construct in our framework. Intrinsic value or "enjoyment" derives from the appreciation of an experience for its own sake, apart from any other consequence that may result (Holbrook, 1994). Applying this to our research context, "enjoyment" results from the fun and playfulness of the online shopping experience, rather than from shopping task completion. The purchase of goods may be incidental to the experience of online shopping. Thus, "enjoyment" reflects consumers' perceptions regarding the potential entertainment of Internet shopping. Childers et al. (2001) found "enjoyment" to be a consistent and strong predictor of attitude toward online shopping. If consumers enjoy their online shopping experience, they have a more positive attitude toward online shopping, and are more likely to adopt the Internet as a shopping medium.

In our framework, we identify three latent dimensions of "enjoyment" construct, including "escapism", "pleasure", and "arousal" (Menon and Kahn, 2002; Mathwick et al., 2001). "Escapism" is reflected in the enjoyment that comes from engaging in activities that are absorbing, to the point of offering an escape from the demands of the day-to-day world. "Pleasure" is the degree to which a person feels good, joyful, happy, or satisfied in online shopping, whereas "arousal" is the degree to which a person feels stimulated, active or alert during the online shopping experience. A pleasant or arousing experience will have carry-over effects on the next experience encountered (Menon and Kahn, 2002). If consumers are exposed initially to pleasing and arousing stimuli during their Internet shopping experience, they are then more likely to engage in subsequent shopping behavior: they will browse more, engage in more unplanned purchasing, and seek out more stimulating products and categories.

\section{Exogenous factors}

TAM is criticized for ignoring the social influence on technology acceptance (Chen et al., 2002; Moon and Kim, 2001). Although "ease of use", "usefulness", and "enjoyment" are believed to be fundamental in determining the acceptance and use of various corporate information technologies (Davis, 1989, 1993), these beliefs, however, may not explain consumers' behavior toward newly emerging technologies, such as Internet shopping. Factors contributing to the acceptance 
IJSIM

15,1

110

of a new IT are likely to vary with the technology, target users, and context (Moon and Kim, 2001). Thus, for our specific online shopping context, additional explanatory factors are needed beyond the usefulness, ease of use, and enjoyment constructs. Therefore, a total of five exogenous factors are incorporated in our framework for understanding consumers' attitude and intention toward online shopping: "consumer traits", "situational factors", "product characteristics", "previous online shopping experiences", and "trust in online shopping". These exogenous factors are key drivers in moving consumers to ultimately adopt the Internet as a shopping medium. The different ways in which consumers' intention to shop online is influenced by these exogenous factors are discussed in this section.

\section{Consumer traits}

Consumer traits that are of interest in understanding why consumers shop on the Internet include demographic factors and personality characteristics. Four relevant demographic factors - age, gender, education, and income - (Burke, 2002) have a significant moderating effect on the relationship between the three basic determinants "ease of use", "usefulness", and "enjoyment" and consumers' attitude toward online shopping. The influence of age is noticeable through the fact that compared to older consumers, younger adults, especially those under age 25, are more interested in using new technologies, like the Internet, to find out about new products, search for product information, and compare and evaluate alternatives (Wood, 2002). A reason for this is that older consumers may perceive the benefits of Internet shopping to be less than the cost of investing in the skill needed to do it effectively, and therefore avoid shopping on the Internet (Ratchford et al., 2001). Next to the higher interest in using new technologies, consumers younger than age 25 are the group most interested in having fun while shopping. They respond more favorably than older shoppers to features that make online shopping entertaining. When it comes to gender, men express a greater interest in using various types of technology in the shopping process. They are more positive about using the Internet as a shopping medium, whereas female shoppers prefer using catalogs to shop at home. But the female consumers that do prefer to shop on the Internet, shop more frequently online than their male counterparts (Burke, 2002; Li et al., 1999). Education also plays a moderating role in the relationship between the three basic determinants and consumers' attitude toward online shopping. Higher educated consumers are more comfortable using non-store channels, like the Internet to shop (Burke, 2002). A reason for this is that education is often positively correlated with an individual's level of Internet literacy (Li et al., 1999). A final demographic factor of interest is income. Consumers with higher household incomes (above $\$ 75,000$ annually) intend to shop more online compared to lower income consumers. A reason for this is that higher household incomes are often positively correlated 
with possession of computers, Internet access and higher education levels of consumers (Lohse et al., 2000).

Next to these demographic factors, personality characteristics also have a moderating effect on the relationship between "ease of use", "usefulness", and "enjoyment" and consumers' attitude toward shopping on the Internet. In our research context, relevant personality traits are "expertise" (Ratchford et al., 2001; Alba and Hutchinson, 1987), "self-efficacy" (Eastin and LaRose, 2000; Marakas et al., 1998; Bandura, 1994), and "need for interaction" (Dabholkar and Bagozzi, 2002; Dabholkar, 1996). "Expertise" is defined as an individual's level of knowledge or skill. In order to shop on the Internet, a considerable amount of knowledge or skill is required. Aside from the basic knowledge of computer use, consumers also have to learn the skills needed to obtain the desired information on the Internet. Because learning to shop on the Internet is costly and time-consuming for those who are computer illiterate to start with, consumers weigh the costs and benefits before deciding whether to invest in learning the required skills. Since learning-by-doing is an important component of acquiring such skills, those who have the most experience at shopping on the Internet are likely to be the most skilled (Ratchford et al., 2001). Once consumers have the required level of knowledge and skills to shop on the Internet, this will attenuate the relationship between "ease of use" and "usefulness" and their attitude toward online shopping, because these factors are then of less influence to them in forming a positive attitude toward shopping on the Internet.

A personality characteristic that is closely related to expertise is self-efficacy. "Self-efficacy" refers to individuals' beliefs that they have the ability and the resources to successfully perform a specific task (Bandura, 1994). Since online shopping requires basic knowledge of computer use as well as knowledge about the Internet, a distinction has been made in this context between "computer self-efficacy" and "Internet self-efficacy". Marakas et al. (1998) define general "computer self-efficacy" as an individual's judgment of efficacy across multiple computer application domains, whereas "Internet self-efficacy" is a person's judgment of his or her ability to apply Internet skills in a more encompassing mode, such as finding information or troubleshooting search problems (Eastin and LaRose, 2000). Thus, consumers with low self-efficacy are uncertain and less comfortable shopping on the Internet, and therefore need simple procedures that require little knowledge and guide them through the online shopping process. This indicates that, in case of low self-efficacy, the level of "ease of use" of Internet as a shopping medium must be high in order to achieve a positive attitude toward online shopping. On the other hand, high degrees of computer self-efficacy and Internet self-efficacy proved to have an attenuating effect on the relationship between "usefulness" and attitude toward using the Internet (Eastin and LaRose, 2000). A reason for this attenuating effect is that self-efficacy judgments are positively related to 
IJSIM

15,1

112

outcome expectations (Oliver and Shapiro, 1993). The stronger a person's self-efficacy beliefs, the more likely he or she tries to achieve the desired outcome. In addition to this, it is explained by the fact that consumers are more likely to attempt and persist in behaviors that they feel capable of performing (Eastin and LaRose, 2000).

A final personality characteristic that is of relevance in the context of online shopping is the "need for interaction" with a service employee or salesperson (Dabholkar and Bagozzi, 2002). This "need for interaction" is defined as the importance of human interaction to the consumer in service encounters (Dabholkar, 1996). In online shopping, the human interaction with a service employee or salesperson is replaced by help-buttons and search features. Therefore, consumers with a high "need for interaction" will avoid shopping on the Internet, whereas consumers with a low "need for interaction" will seek such options (Dabholkar and Bagozzi, 2002). This implicates that the consumer characteristic "need for interaction" has a strengthening effect on the relationship between the three basic determinants and consumers' attitude toward Internet shopping. Owing to the lack of physical contact with service employees and sales persons in an online shopping environment, these relationships need to be stronger in order for consumers with a high need for interaction to have a positive attitude toward shopping online.

\section{Situational factors}

In order to fully understand consumers' motivations to engage in online shopping, situational factors have to be taken into account as well. A wide variety of situational aspects can moderate the relationship between attitude and consumers' intention to shop on the Internet, but for the purpose of this paper only the most relevant are discussed: "time pressure", "lack of mobility", "geographical distance", "need for special items" and attractiveness of alternatives". To most consumers important attributes of online shopping are convenience and accessibility (Wolfinbarger and Gilly, 2001): because consumers can shop on the Internet in the comfort of their home environment, it saves time and effort, and they are able to shop any time of the day or night. Especially for consumers that, owing to their extended working hours, only have a small amount of free time, online shopping is an excellent opportunity. Thus, the situational factor "time pressure" has an attenuating impact on the relationship between attitude and consumers' intention to shop online. Because the Internet is time saving and accessible 24 hours a day, this becomes the main drive for online shopping and attitude toward Internet shopping is less important. A second situational factor is "lack of mobility" (Avery, 1996). Consumers who are not able to shop in traditional stores owing to an illness or other immobilizing factors, have the ability to shop on the Internet to fulfill their shopping goals. Furthermore, for consumers who have to travel large distances to stores that provide them with the articles 
needed, shopping on the Internet is a viable alternative to overcome this "geographical distance". A fourth situational factor that attenuates the relationship between attitude and consumers' intention to shop online is the "need for special items" (Wolfinbarger and Gilly, 2001). In case consumers need to acquire tailored products, like special sized clothing or large sized shoes, that are not available in conventional stores, shopping on the Internet is an option for them to purchase these special items anyhow. Finally, the last situational factor that moderates the relationship between attitude and intention is "attractiveness of alternatives". In case consumers are drawn by the attractiveness of a certain store in their neighborhood that, for example, sells the same products as the online store, the relationship between attitude and intention will be attenuated. The reason for this is that the consumer, although he might have a positive attitude toward online shopping, is lead by the strong attractiveness of the brick-and-mortar alternative. Therefore, he will choose to shop offline, despite his positive attitude toward shopping on the Internet.

\section{Product characteristics}

Consumers' decisions whether or not to shop online are also influenced by the type of product or service under consideration. Some product categories are more suitable for online shopping than other categories. The lack of physical contact and assistance in shopping on the Internet is one factor that influences this suitability. Another factor is the need to feel, touch, smell, or try the product, which is not possible when shopping online. Following this, clearly standardized and familiar products such as books, videotapes, CDs, groceries, and flowers, have a higher potential to be considered when shopping on the Internet, especially since quality uncertainty in such products is virtually absent, and no physical assistance or pre-trial is needed (Grewal et al., 2002; Reibstein, 1999). On the other hand, personal-care products like perfume and lotion, or products that require personal knowledge or experience like computers and cars, are less likely to be considered while shopping online (Elliot and Fowell, 2000). Thus, if personal interaction with a salesperson is required for the product under consideration, consumers' intention to shop on the Internet is low. Furthermore, if consumers need to pre-trial the product under consideration, or have the necessity to feel, touch or smell the product, then their intention to shop online is low as well. However, in case of standardized and familiar goods, or certain sensitivity products that require a level of privacy and anonymity, consumers' intention to shop on the Internet is high (Grewal et al., 2002).

\section{Previous online shopping experiences}

Intention to shop online is also influenced by consumers' Internet shopping history (Shim et al., 2001). It is demonstrated by past research findings that prior online shopping experiences have a direct impact on Internet shopping intentions (Eastlick and Lotz, 1999; Weber and Roehl, 1999). Helson (1964) 
IJSIM

15,1

\section{4}

suggests that an individual's response to a judgmental task is based on three aspects:

(1) Sum of the individual's past experiences.

(2) The context or background.

(3) The stimulus.

To the extent that minimal context or system-specific information is given, the individual will make system-specific evaluations based on prior experiences with the system. In the online shopping context, consumers evaluate their Internet shopping experiences in terms of perceptions regarding product information, form of payment, delivery terms, service offered, risk involved, privacy, security, personalization, visual appeal, navigation, entertainment and enjoyment (Burke, 2002; Parasuraman and Zinkhan, 2002; Mathwick et al., 2001). In case prior online shopping experiences resulted in satisfactory outcomes and were evaluated positively, this leads consumers to continue to shop on the Internet in the future (Shim et al., 2001). Such past experiences decrease consumers' perceived risk levels associated with online shopping. However, if these past experiences are judged negatively, consumers are reluctant to engage in online shopping in future occasions. This illustrates the importance of turning existing Internet shoppers into repeat shoppers by providing them with satisfying online shopping experiences (Weber and Roehl, 1999).

\section{Trust in online shopping}

Lack of trust is one of the most frequently cited reasons for consumers not shopping on the Internet (Lee and Turban, 2001). Since this shopping medium is relatively new and most of them have only little experience with it, shopping on the Internet provides a challenge to many consumers. Rotter (1971) has found that in novel situations, people rely on their general disposition to trust. The most salient source of trust in a retail setting is the salesperson, where consumer trust is dependent on the salesperson's expertise, likeability, and similarity to the customer (Doney and Cannon, 1997). However, with online shopping this physical salesperson is replaced by help buttons and search features, thus removing the basis of consumer trust in the shopping experience (Lohse and Spiller, 1998). Furthermore, online shopping also contains a level of risk. Consumers cannot physically check the quality of a product or monitor the safety and security of sending sensitive personal and financial information while shopping on the Internet (Lee and Turban, 2001). This condition creates a sense of powerlessness among online shoppers. Therefore trust has an important moderating effect on the relationship between consumers' attitude toward Internet shopping and intention to shop online.

The complexity of examining consumer trust in Internet shopping and its determinants lies in the fact that online shopping involves trust not simply 
between the Web shop and the consumer (interpersonal trust), but also between the consumer and the computer system, i.e. the Internet (institutional trust) (McKnight and Chervany, 2001-2002). Next to this, contextual factors like security and privacy have an impact on consumer trust in shopping on the Internet (Lee and Turban, 2001). A high level of security and privacy in the online shopping experience has a positive effect on consumer trust, owing to the lowered risk involved with exchanging information. In general, the level of 115 trust, interpersonal as well as institutional, is positively related to consumers' attitude and intention to shop on the Internet. Violation of consumers' trust in online shopping, in terms of privacy invasion or misuse of personal information, negatively influences attitude toward online shopping and leads to reluctant behavior among consumers to shop on the Internet in future occasions.

\section{Future research avenues for comparing online shopping with traditional shopping}

After identifying the factors that affect consumers' attitude and intention to shop online and placing them in our proposed framework, the next step is to investigate the differences, similarities, advantages and disadvantages of Internet shopping compared to shopping in brick-and-mortar stores, so-called traditional or real world shopping. Current retailing trends show a shift from traditional store-based retailing to an increased use of the Internet (Keen et al., 2002). In the past few years, many businesses have faced the challenge of incorporating e-commerce into their repertoire of services in order to serve their customers 24/7. However, in establishing an online presence next to their existing physical stores, retailers encounter the difficulty of not being able to use the same format for both online and traditional stores. Although online shopping incorporates many of the same characteristics as "real world shopping" (Chen and Leteney, 2000; Lohse and Spiller, 1999), consumers are in a different frame of mind and have different informational needs when shopping on the Internet or the traditional way (Burke, 2002). Therefore, it is important to first identify the analogies and differences between traditional shopping features and features of online shopping before setting up a format. Second, retailers have to be aware of the advantages and disadvantages of online shopping compared to traditional shopping to understand consumers' motives to choose one channel over the other. Lohse and Spiller (1999) set up a table to provide an overview on how the features of a brick-and-mortar store relate to an Internet store. In Table I we have translated these store-features to features relating to online and traditional shopping. The table shows that all traditional shopping features are also present in online shopping, but in most cases in a somewhat different form and not always on a level satisfactory to consumers. For instance, Internet shoppers are not able to gain the experience they usually get when shopping the traditional way, e.g. interacting with a 


\section{IJSIM \\ 15,1}

116

Sales promotion

Store window displays

Store atmosphere

Aisle products

Store layout

Number of floors in the store

Number of store entrances and store outlets/branches

Checkout cashier

Look and touch of the merchandise

Number of people entering the store

Table I.

Online shopping vs. traditional shopping
Sales per period

Source: Lohse and Spiller (1999)
Online shopping

Product descriptions, information pages, gift services, search function, clerk on the phone/e-mail

Special offers, online games and lotteries, links to other sites of interest, appetizer information

Home page

Interface consistency, store organization, interface and graphics quality

Featured products on hierarchical levels of the store

Screen depth, browse and search functions, indices, image maps

Hierarchical levels of the store

Number of links to a particular online retail store

Online shopping basket and/or order form

Limited to image quality and description, potential for sound and video applications

Number of unique visits to the online retail store

Sales per period

salesperson, feeling the atmosphere, and touching or trying the merchandise (Li et al., 1999). In cases where these features are specifically important to consumers, they will choose to engage in traditional shopping over online shopping.

Nevertheless, Internet shopping fulfills several consumer needs more effectively and efficiently than conventional shopping (Grewal et al., 2002; Chen and Leteney, 2000; Häubl and Trifts, 2000; Alba et al., 1997). First, with online shopping, consumers can browse the entire product-assortment with minimal effort, inconvenience and time investment. Second, consumers can efficiently obtain critical knowledge about firms, products and brands, and thereby increase their competency in making sound decisions while shopping. Third, consumers can easily compare product features, availability, and prices more efficiently and effectively than with brick-and-mortar shopping.

Fourth, Internet shopping provides a level of anonymity when shopping for certain sensitive products. Fifth, online shopping offers a high level of convenience for those whose time costs are perceived to be too high to invest in conventional shopping (Grewal et al., 2002).

In our opinion, online shopping is not just another way of shopping that provides consumers with the same outcome at the end of the process as, for example, with traditional shopping. Indeed, online shopping provides consumers with added value, but can also withhold them from certain 
sources of value. As an illustration of this concept, we take the example of e-banking: by using online banking for making transactions or checking their account balance, consumers save time because they don't have to go to the banking office in person during or after working hours. The precious time they save by e-banking provides them with the opportunity to spend this time on other activities like, for example, sports, leisure, and family and thus create added value through online banking. However, this process also withholds them from sources of value they would get when going to the banking office in person, e.g. the social value of personal contact with banking employees and other clients of the bank.

Thus, there are several reasons for consumers to prefer Internet shopping over "real world shopping". However, even though these advantages may lead some consumers to prefer online shopping, they are not necessarily choosing one shopping channel over another. Instead, consumers are shopping wherever and whenever it is convenient to them, whether by store, catalog, or Internet (Cyr, 2000). Today's consumers are multi-channel shoppers, and some occasions prefer traditional off-line shopping to shopping on the Internet.

\section{Implications for researchers}

This paper provides a framework that helps researchers understand the drivers of consumers' attitude and intention to shop on the Internet, and consumers' perceptions regarding ease of use, usefulness, and enjoyment. At the same time, behavioral intention to shop online is also affected by exogenous factors incorporated in our framework. From the standpoint of technology acceptance research, this paper extends the technology acceptance model with these exogenous factors. Although TAM emphasizes the importance of usefulness as the key determinant of user acceptance of new technologies, with Internet shopping this does not necessarily have to be the case. Ease of use, enjoyment, or even one of the exogenous factors in our framework might have a more significant effect on consumers' attitude and intention in the online shopping context than usefulness. Therefore, further research is needed to determine which of the factors in our framework have the most significant effect on behavioral intention to shop on the Internet. We do not believe that a general answer to this question is realistic, since the context of online shopping deals with different consumers that have different needs and goals in different situations. However, an attempt could be made to filter out the relatively less significant factors and/or determine relevant situational differences and set up a new conceptual framework.

\section{Implications for practitioners}

The framework we propose is of relevance to both e-marketers and e-tailers, since it enables them to assess the features that specifically attract consumers to shop on the Internet. Understanding consumers' motivations and limitations 
IJSIM

15,1

118

to shop online is of major importance in e-tailing for making adequate strategic, technological, and marketing decisions to increase customer satisfaction, as well as improving web site design of virtual stores. For instance, our framework shows that consumers' attitude toward online shopping is not only strongly influenced by utilitarian aspects, but is also significantly predicted by hedonic factors like "enjoyment". Therefore, e-marketers should emphasize the enjoyable aspect of shopping on the Internet in their promotions as well. Next to this, consumer characteristics also affect their attitude and intention toward online shopping, which implicates that e-tailers should not treat all consumers alike. Furthermore, we stated that lack of trust is one of the major reasons for consumers not shopping on the Internet. Thus, in order for consumers to engage in trust-related Internet behavior like online shopping, the e-vendor must make trust-building interventions such as posting a privacy policy, use a third-party seal, interact with customers, advertise its good reputation, link to other reputable sites, or offer guarantees (McKnight and Chervany, 2001-2002). Finally, Internet retailers must insure that consumers have a positive shopping experience each time the consumer visits the online store (Keen et al., 2002).

\section{Limitations}

As with any conceptual model, our model also has its limitations. First of all, we have set up a conceptual framework that includes all factors considered to drive consumers to shop online. Although we based our framework on a combination of results from many different studies on the subject of online shopping, technology acceptance and the acceptance of the Internet as a shopping medium in particular, there can always be factors of influence on consumers' intention to shop on the Internet that are not included in the literature to date, or that is addressed in other literature studies. However, we are confident that we have given an overview of the most relevant factors in this context. A second limitation of our paper is that we centered it around a framework that is the result of a literature review and has never been tested in its entirety using empirical evidence. This implies that some caution should be taken in applying the findings that can be derived from our framework. Furthermore, we have defined "online shopping" as the use of online stores by consumers up until the transactional stage of purchasing and logistics. Undoubtedly, this is not the correct definition, since shopping on the Internet is considered to be a process that goes beyond the boundaries of just browsing web stores. Finally, by selecting a specific structure for our review, we have necessarily limited the number of previous research results that were discussed in this paper.

\section{Conclusion}

While a large number of consumers in the US and Europe frequently shop on the Internet, research on what drives consumers to shop online has typically been fragmented. In this paper, we therefore propose a framework to increase 
researchers' understanding of consumers' attitude toward online shopping and their intention to shop on the Internet. The framework uses the constructs of TAM as a basis, extended by exogenous factors and applies it to the online shopping context. Our review shows that attitude toward online shopping and intention to shop online are not only affected by ease of use, usefulness, and enjoyment, but also by exogenous factors like consumer traits, situational factors, product characteristics, previous online shopping experiences, and trust in online shopping.

\section{References}

Alba, J.W. and Barton Weitz, J.L. (1997), "Interactive home shopping: consumer, retailer, and manufacturer incentives to participate in electronic marketplaces", Journal of Marketing, Vol. 61, July, pp. 38-53.

Alba, J.W. and Hutchinson, J.W. (1987), "Dimensions of consumer expertise", Journal of Consumer Research, Vol. 13 No. 4, pp. 411-54.

Avery, R.J. (1996), "Determinants of search for non-durable goods: an empirical assessment of the economics of information theory", The Journal of Consumer Affairs, Vol. 30 No. 2 , pp. 390-406.

Babin, B.J., Darden, W.R. and Griffin, M. (1994), "Work and/or fun: measuring hedonic and utilitarian shopping value", Journal of Consumer Research, Vol. 20, pp. 644-56.

Bandura, A. (1994), Self-efficacy: The Exercise of Control, W.H. Freeman, New York, NY.

Bobbitt, L.M. and Dabholkar, P.A. (2001), "Integrating attitudinal theories to understand and predict use of technology-based self-service: the internet as an illustration", International Journal of Service Industry Management, Vol. 12 No. 5, pp. 423-50.

Brown, S.P., Challagalla, G. and Ganesan, S. (2001), "Self-efficacy as a moderator of information-seeking effectiveness", Journal of Applied Psychology, Vol. 86 No. 5, pp. 1043-51.

Burke, R.R. (2002), "Technology and the customer interface: what consumers want in the physical and virtual store", Journal of the Academy of Marketing Science, Vol. 30 No. 4 , pp. 411-32.

Chen, L., Gillenson, M.L. and Sherrell, D.L. (2002), "Enticing online consumers: an extended technology acceptance perspective", Information \& Management, Vol. 39 No. 8, pp. 705-19.

Chen, S. and Leteney, F. (2000), "Get real! Managing the next stage of internet retail", European Management Journal, Vol. 18 No. 5, pp. 519-28.

Childers, T.L., Carr, C.L., Peck, J. and Carson, S. (2001), "Hedonic and utilitarian motivations for online retail shopping behavior", Journal of Retailing, Vol. 77 No. 4, pp. 511-35.

Cyr, D. (2000), "Your new customer", Catalog Age, Vol. 18 No. 8, pp. 125-30.

Dabholkar, P.A. (1996), "Consumer evaluations of new technology-based self-service options", International Journal of Research in Marketing, Vol. 13 No. 1, pp. 29-51.

Dabholkar, P.A. and Bagozzi, R.P. (2002), “An attitudinal model of technology-based self-service: moderating effects of consumer traits and situational factors", Journal of the Academy of Marketing Science, Vol. 30 No. 3, pp. 184-201.

Davis, F.D. (1989), "Perceived usefulness, perceived ease of use, and user acceptance of information technology", MIS Quarterly, Vol. 13 No. 3, pp. 319-40.

Davis, F.D. (1993), "User acceptance of information technology: system characteristics, user perceptions and behavioral impacts", International Journal of Man-Machine Studies, Vol. 38 No. 3, pp. 475-87. 
IJSIM

15,1

120
Davis, F.D., Bagozzi, R.P. and Warshaw, P.R. (1989), "User acceptance of computer technology: a comparison of two theoretical models", Management Science, Vol. 35 No. 8, pp. 982-1003.

Davis, F.D., Bagozzi, R.P. and Warshaw, P.R. (1992), "Extrinsic and intrinsic motivation to use computers in the workplace", Journal of Applied Social Psychology, Vol. 22 No. 14, pp. 1109-30.

Doney, P.M. and Cannon, J.P. (1997), "An examination of the nature of trust in buyer-seller relationships", Journal of Marketing, Vol. 61 No. 2, pp. 35-51.

Eastin, M.S. and LaRose, R. (2000), "Internet self-efficacy and the psychology of the digital divide", Journal of Computer-Mediated Communication, Vol. 6 No. 1, available at: www.ascusc.org/jcmc/

Eastlick, M.A. and Lotz, S.L. (1999), "Profiling potential adopters of an interactive shopping medium", International Journal of Retail and Distribution Management, Vol. 27 No. 6/7, pp. 209-23.

Elliot, S. and Fowell, S. (2000), "Expectations versus reality: a snapshot of consumer experiences with Internet retailing", International Journal of Information Management, Vol. 20 No. 5 , pp. 323-36.

Forrester Research (2001), "Online shopping speeds up as UK Internet users mature reveals Forrester's latest UK Internet user monitor", 5 December, available at: www.forrester .com/ER/Press/Release/0,1769,659,000,htm

GfK Group (2002), available at: www.gfk.com/investor/finanzberichte/gb2002english/index.

Grewal, D., Iyer, G.R. and Levy, M. (2002), "Internet retailing: enablers, limiters and market consequences", Journal of Business Research.

Häubl, G. and Trifts, V. (2000), "Consumer decision making in online shopping environments: the effects of interactive decision aids", Marketing Science, Vol. 19 No. 1, pp. 4-21.

Helson, H. (1964), Adaptation-Level Theory, Harper \& Row, New York, NY.

Hirschman, E.C. and Holbrook, M.B. (1982), "Hedonic consumption: emerging concepts, methods and propositions", Journal of Marketing, Vol. 46 No. 3, pp. 92-101.

Holbrook, M.B. (1994), "The nature of customer value: an axiology of services in the consumption experience", in Rust, R.T. and Oliver, R.L. (Eds), Service Quality: New Directions in Theory and Practice, Sage, Newbury Park, CA, pp. 21-71.

Keen, C., Wetzels, M., de Ruyter, K. and Feinberg, R. (2002), "E-tailers versus retailers: which factors determine consumer preferences?", Journal of Business Research.

Lederer, A.L., Maupin, D.J., Sena, M.P. and Zhuang, Y. (2000), “The technology acceptance model and the World Wide Web", Decision Support Systems, Vol. 29 No. 3, pp. 269-82.

Lee, M.K.O. and Turban, E. (2001), “A trust model for consumer internet shopping”, International Journal of Electronic Commerce, Vol. 6 No. 1, pp. 75-91.

Li, H., Kuo, C. and Russell, M.G. (1999), "The impact of perceived channel utilities, shopping orientations, and demographics on the consumer's online buying behavior", Journal of Computer-Mediated Communication, Vol. 5 No. 2, available at: www.ascusc.org/jcmc/

Lohse, G.L. and Spiller, P. (1998), "Electronic shopping", Communications of the ACM, Vol. 41 No. 7, pp. 81-7.

Lohse, G.L. and Spiller, P. (1999), "Internet retail store design: how the user interface influences traffic and sales", Journal of Computer-Mediated Communication, Vol. 5 No. 2, available at: www.ascusc.org/jcmel

Lohse, G.L., Bellman, S. and Johnson, E.J. (2000), "Consumer buying behavior on the internet: findings from panel data", Journal of Interactive Marketing, Vol. 14 No. 1, pp. 15-29.

Marakas, G.M., Yi, M.Y. and Johnson, R.D. (1998), "The multilevel and multifaceted character of computer self-efficacy: toward clarification of the construct and an integrative framework for research", Information Systems Research, Vol. 9 No. 2, pp. 126-63. 
Mathwick, C., Malhotra, N.K. and Rigdon, E. (2001), "Experiential value: conceptualization, measurement and application in the catalog and Internet shopping environment", Journal of Retailing, Vol. 77 No. 1, pp. 39-56.

Mathwick, C., Malhotra, N.K. and Rigdon, E. (2002), "The effect of dynamic retail experiences on experiential perceptions of value: an Internet and catalog comparison", Journal of Retailing, Vol. 78 No. 1, pp. 51-60.

McKnight, D.H. and Chervany, N.L. (2001-2002), "What trust means in e-commerce customer relationships: an interdisciplinary conceptual typology", International Journal of Electronic Commerce, Vol. 6 No. 2, pp. 35-59.

Menon, S. and Kahn, B. (2002), "Cross-category effects of induced arousal and pleasure on the Internet shopping experience", Journal of Retailing, Vol. 78 No. 1, pp. 31-40.

Moon, J.-W. and Kim, Y.-G. (2001), "Extending the TAM for a World-Wide-Web context", Information \& Management, Vol. 38 No. 4, pp. 217-30.

O'Cass, A. and Fenech, T. (2002), "Web retailing adoption: exploring the nature of Internet users web retailing behavior", Journal of Retailing and Consumer Services, (forthcoming).

Oliver, T.A. and Shapiro, F. (1993), "Self-efficacy and computers", Journal of Computer-Based Interactions, Vol. 20 No. 1, pp. 81-5.

Parasuraman, A. and Zinkhan, G.M. (2002), "Marketing to and serving customers through the Internet: an overview and research agenda", Journal of the Academy of Marketing Science, Vol. 30 No. 4, pp. 286-95.

Ratchford, B.T., Talukdar, D. and Lee, M.-S. (2001), "A model of consumer choice of the internet as an information source", International Journal of Electronic Commerce, Vol. 5 No. 3, pp. 7-21.

Reibstein, D.J. (1999), "Who is buying on the Internet, 1999?" Working Paper, The Wharton School, University of Philadelphia, Philadelphia, PA.

Reinhardt, A. and Passariello, C.W. (2002), "E-commerce starts to click”, Business Week, No. 3796, p. 56.

Rotter, J.B. (1971), "Generalized expectancies for interpersonal trust”, American Psychologist, Vol. 26 No. 5, pp. 443-52.

Shim, S., Eastlick, M.A., Lotz, S.L. and Warrington, P. (2001), "An online prepurchase intentions model: the role of intention to search", Journal of Retailing, Vol. 77 No. 3, pp. 397-416.

Venkatesh, V. (2000), "Veterminants of perceived ease of use: integrating control, intrinsic motivation, and emotion into the technology acceptance model", Information Systems Research, Vol. 4 No. 4, pp. 342-65.

Venkatesh, V. and Speier, C. (1999), "Computer technology training in the workplace: a longitudinal investigation of the effect of the mood", Organizational Behavior and Human Decision Processes, Vol. 79 No. 1, pp. 1-28.

Venkatesh, V. and Speier, C. (2000), "Creating an effective training environment for enhancing telework", International Journal of Human-Compute Studies, Vol. 52 No. 1, pp. 991-1005.

Weber, K. and Roehl, W.S. (1999), "Profiling people searching for and purchasing travel products on the world wide web", Journal of Travel Research, Vol. 37, pp. 291-8.

Wolfinbarger, M. and Gilly, M.C. (2001), "Shopping online for freedom, control, and fun", California Management Review, Vol. 43 No. 2, pp. 34-55.

Wood, S.L. (2002), "Future fantasies: a social change perspective of retailing in the 21st century", Journal of Retailing, Vol. 78 No. 1, pp. 77-83.

Yoon, S.-J. (2002), "The antecedents and consequences of trust in online purchase decisions", Journal of Interactive Marketing, Vol. 16 No. 2, pp. 47-63.

Zeithaml, V., Parasuraman, A. and Malhotra, A. (2002), "Service quality delivery through web sites: a critical review of extant knowledge", Journal of the Academy of Marketing Sciences, Vol. 30 No. 4, pp. 362-75. 